\title{
Experimental Study for Vibration Behaviors of Locally Defective Deep Groove Ball Bearings under Dynamic Radial Load
}

\author{
V. N. Patel, ${ }^{1}$ N. Tandon, ${ }^{2}$ and R. K. Pandey ${ }^{3}$ \\ ${ }^{1}$ G H Patel College of Engineering and Technology, Vallabh Vidyanagar 388120, India \\ ${ }^{2}$ Industrial Tribology, Machine Dynamics and Maintenance Engineering Centre (ITMMEC), I.I.T. Delhi, New Delhi 110 016, India \\ ${ }^{3}$ Department of Mechanical Engineering, I.I.T. Delhi, New Delhi 110 016, India
}

Correspondence should be addressed to V. N. Patel; vinodgcet1@gmail.com

Received 11 February 2014; Accepted 29 April 2014; Published 18 May 2014

Academic Editor: Abdelkrim Khelif

Copyright (C) 2014 V. N. Patel et al. This is an open access article distributed under the Creative Commons Attribution License, which permits unrestricted use, distribution, and reproduction in any medium, provided the original work is properly cited.

Rolling element bearings are used in many mechanical systems at the revolute joints for sustaining the dynamic loads. Thus, the reliable and efficient functioning of such systems critically depends on the good health of the employed rolling bearings. Hence, health monitoring of rolling bearings through their vibration responses is a vital issue. In this paper, an experimental investigation has been reported related to the vibration behaviours of healthy and locally defective deep groove ball bearings operating under dynamic radial load. The dynamic load on the test bearings has been applied using an electromechanical shaker. The vibration spectra of the healthy and defective deep groove ball bearings in time and frequency domains have been compared and discussed. Overall vibration increases in presence of local defects and dynamic radial load.

\section{Introduction}

Rolling element bearings are used in many mechanisms and machines to achieve the operational objectives. For reliable and efficient functioning of rolling bearings employed in such mechanical systems, their health monitoring in terms of vibration responses is an essential task. Though the rolling bearings are manufactured with maximum care using high precision machine tools, the bearings may develop early defects during their usage depending upon the nature of operating parameters and working environments. It is also worth noticing here that the rolling bearings of several mechanisms and machines are often subjected to dynamic loads. Thus, a need arises to explore the role of bearing defects on its vibration behaviours in presence of dynamic radial load.

Rolling bearings are mainly subjected to vibrations because of inherent nonlinearity, which arises due to Hertzian load deformation relationship, varying compliance, clearance, local and distributed defects, and so forth. Though the vibration studies of bearings in presence of distributed defects have been reported in depth by many researchers [15], in this paper, mainly, articles dealing with the vibrations of locally defective rolling bearings have been reviewed and reported. Among some prior studies, McFadden and Smith $[6,7]$ have presented a simple model to describe the vibrations of rolling element bearings in presence of single and multiple point local defects on the inner races. A comparison of predicted and measured vibration spectra is also provided by the authors with relevant discussions. Later on, Su and Lin [8] have extended the model reported in [6] for describing the bearings' vibrations under various types of loadings. The vibration and acoustic measurement techniques for defect detection of rolling bearings have been nicely summarised by Tandon and Choudhury [9] for ready reference to researchers. Sopanen and Mikkola [10, 11] have proposed a dynamic model for vibrations study of deep groove ball bearings in the presence of bearing defects. The authors have incorporated the influence of lubrication and nonlinear deformation at the Hertzian contacts formed between the balls and races. In a simplified model, Choudhury and Tandon [12] have considered lumped masses of the 
shaft and housing on the vibration response of the locally defective rolling element bearings.

Vibration responses of rolling ball bearings in presence of local defects also have been investigated by many researchers [13-20] using their respective numerical models. Patil et al. [16] have presented a theoretical model for vibration study of locally defective ball bearings. It has been reported by the authors that the vibration amplitude happens to be large with the local defective outer race rolling bearing in comparison to the local defective inner race and balls. Moreover, Liu et al. [17] have proposed a piecewise response function to describe the vibration response of ball bearings in presence of local defects of different sizes. Recently, an attempt has been made by Patel et al. [20] through a mathematical model to incorporate the influence of dynamic radial load on the vibration response of locally defective rolling bearings. It has been reported by the authors that the vibration amplitude increases in presence of local defect on outer race and dynamic radial load.

Literature review reveals dearth of the papers dealing with vibration study of the healthy and defective rolling bearings subjected to dynamic loadings. It is worth mentioning here that in various mechanisms, robots, and rotating machines the frequency of applied loads on the rolling bearings varies. Thus, it will be much practical to study the vibration behaviours of rolling bearings considering the synergistic effect of local defects (of different size) and dynamic radial loads. Therefore, the objective of this paper is to report the experimental findings related to the vibration behaviours of the healthy and locally defective deep groove ball bearings (SKF BB1 B420205) under dynamic radial load.

\section{Experimental Details}

The vibration studies of healthy and locally defective deep groove ball bearings (designation: SKF BB1 B420205) were carried out using a test rig, which is shown in Figure 1. The rotating shaft of the rig is supported on two deep groove ball bearings (SKF 6311), which are named as supporting bearings (refer to Figure 1). The test bearing (SKF BB1 B420205) was mounted on the shaft that is projected out from the right side supporting bearing. For lubrication of test bearing, commercial grease (LGMT2/1, lithium soap/mineral oil, operating temperature $-30^{\circ}$ to $120^{\circ} \mathrm{C}$ ) has been used. The vibration signals of the test bearings were captured by an accelerometer (B\&K, 4370) mounted on the top of the test bearing housing. The dynamic radial load with varying frequency $(10-1000 \mathrm{~Hz})$ was imparted to the housing of test bearing from the bottom direction through stringer of an electromechanical shaker as illustrated in Figure 1.

Local circular defects on either race of the healthy test bearings were created by electric discharge machining (EDM). Different sizes (diameters of $0.42,0.50,0.96$, and $1.48 \mathrm{~mm}$ ) of defects were generated on the healthy bearings after recording the vibration behaviours of each bearing in their healthy conditions. Figure 2 provides photographic views of the circular defects on test bearing races.
The vibration signals captured from the housing of the test bearing by the accelerometer were amplified by the charge amplifier and transferred to Fast Fourier Transform analyser (ONO SOKKI) followed by processing in MATLAB. All the experiments were carried out at the $1500 \mathrm{rpm}\left(f_{s}=25 \mathrm{~Hz}\right)$ of shaft rotation. The magnitudes of the dynamic force applied to the test bearings were measured by a load sensor attached to the stringer of the shaker. Characteristic defect frequencies of the test bearings fall in the range of $0-200 \mathrm{~Hz}$. Hence, all the experimental results have been reported in this paper for this range of frequency. Figure 3(a) illustrates the dynamic radial load pattern applied on the test bearings (SKF BB1 B420205). The time domain signals (Figure 3(a)) of the dynamic radial load pattern have been converted into the frequency domain using MATLAB codes and the same has been shown in Figure 3(b). The dynamic radial loads were measured, which varied in the range of 30-40 $\mathrm{N}$ in the frequency range of $0-$ $200 \mathrm{~Hz}$.

\section{Results and Discussions}

The vibration spectra of each new deep groove ball bearing (designation: SKF BB1 B420205) were measured by mounting it on the rotating shaft $(1500 \mathrm{rpm})$ without applying any loads for accessing the health in new condition itself. The vibration spectra of a healthy bearing (in new condition) in time domains can be seen in Figures 4(a) and 5(a) without and with dynamic radial load, respectively. However, the corresponding vibration spectra in frequency domains are shown in Figures 4(b) and 5(b). Shaft rotational frequency $(25 \mathrm{~Hz})$ and their harmonics can be seen in these figures. Moreover, Figure 5(b) shows some other frequencies in addition to harmonics. It might be due to the excitation of other components of the test rig. After recording the vibration response of healthy bearings (new bearing), circular defects of different diameters were created on either races of the bearings by electric discharge machining.

3.1. Bearing with Inner Race Defect. Inner race rotates at the shaft rotational speed due to its press fit mounting on the rotating shaft. The ball pass frequency for inner race (BPFI) becomes amplitude modulated due to the shaft rotational frequency. Vibration responses captured at the housings of the test bearings (with circular defects on inner races) have been presented in Figures 6-9. For the shaft's rotational speed of $1500 \mathrm{rpm}$, the ball pass frequency for inner race (BPFI) is computed $123 \mathrm{~Hz}$ using the relation (BPFI = $\left.\left(N_{b} / 2\right) \times\left(N_{s} / 60\right) \times(1+d / D)\right)$. It is difficult to identify the impulses generated during the interaction of defect and balls in the vibration spectra in time domains as shown in Figures 6(a), 7(a), 8(a), and 9(a) for $0.42,0.50,0.96$, and $1.48 \mathrm{~mm}$ defect diameters, respectively. However, the shaft rotational frequency $\left(f_{s}\right)$, ball pass frequency of inner race (BPFI), and side band frequencies (BPFI $\pm f_{s}$ ) are present in the vibration spectra in frequency domain in Figure 6(b). The vibration amplitude at the defect frequency (BPFI = $124.9 \mathrm{~Hz}$ ) is $0.1 \mathrm{~mm} / \mathrm{s}$ which is buried in the vibrations due to dynamic radial loading. Therefore, to identify this defect 

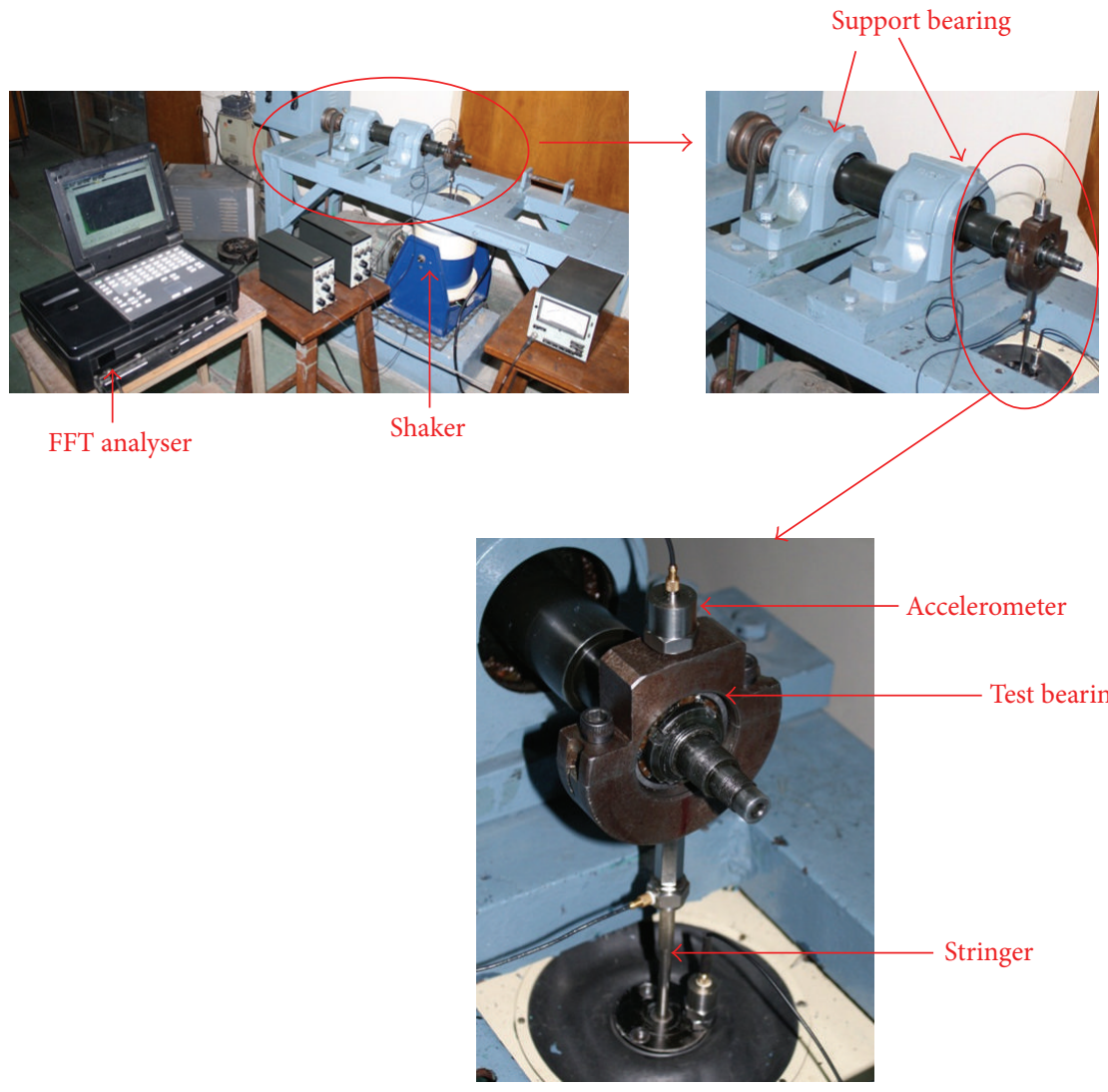

FIGURE 1: Photographic description of experimental setup with a mounted test bearing.
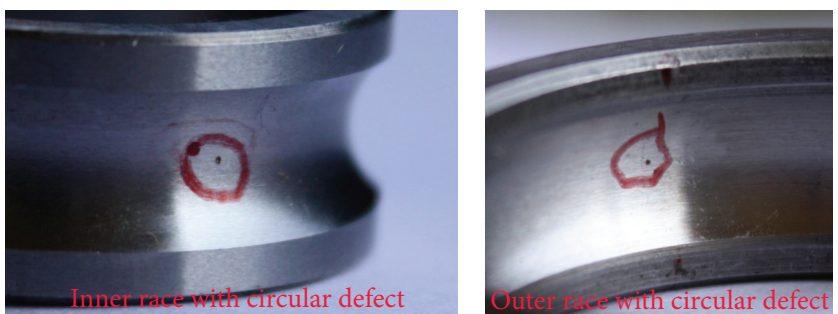

FIGURE 2: Photographic views of circular defects on races.

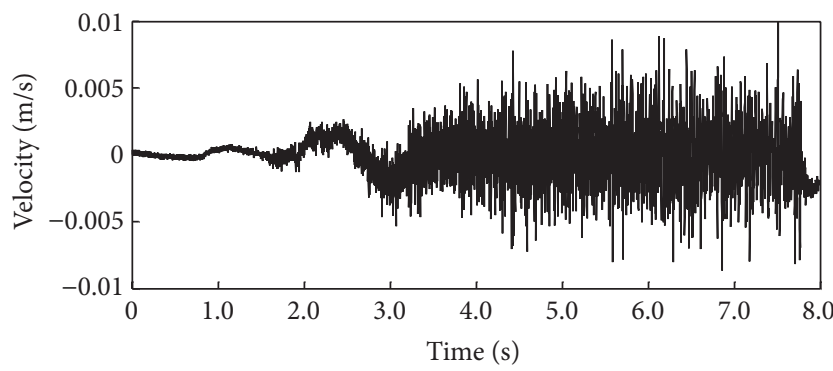

(a) Vibration spectra in time domain

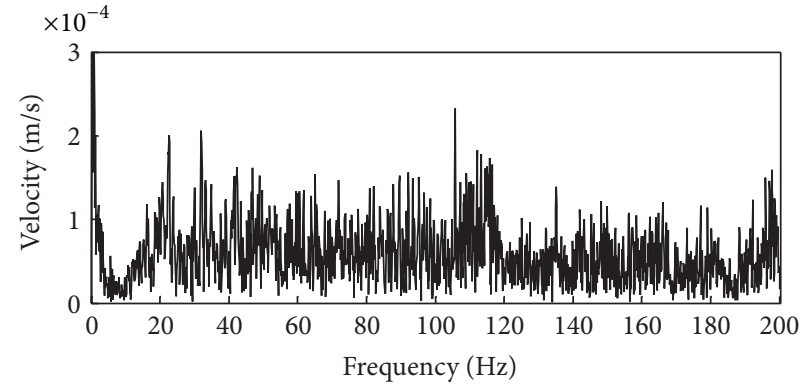

(b) Vibration spectra in frequency domain

FIGURE 3: Dynamic radial load patterns applied on test bearings. 


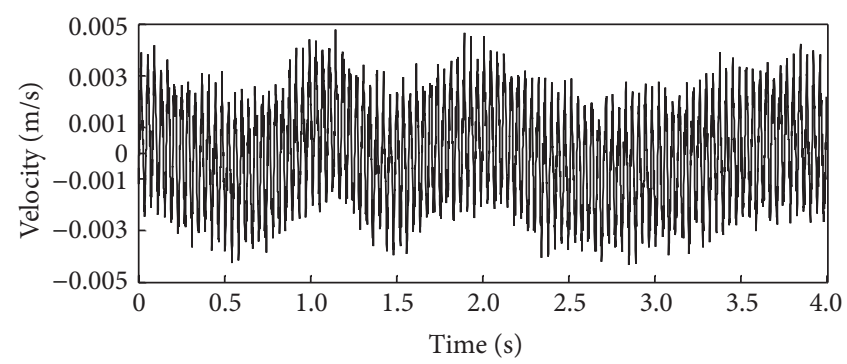

(a) Vibration spectra in time domain

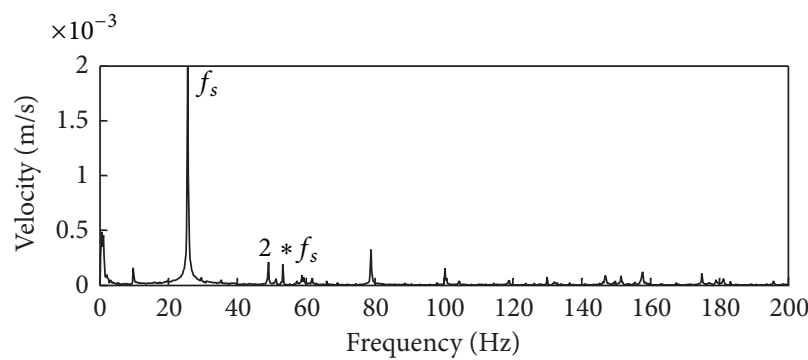

(b) Vibration spectra in frequency domain

FIGURE 4: Vibration responses of healthy (new) test bearing (shaft speed $=1500 \mathrm{rpm}$, unloaded condition).

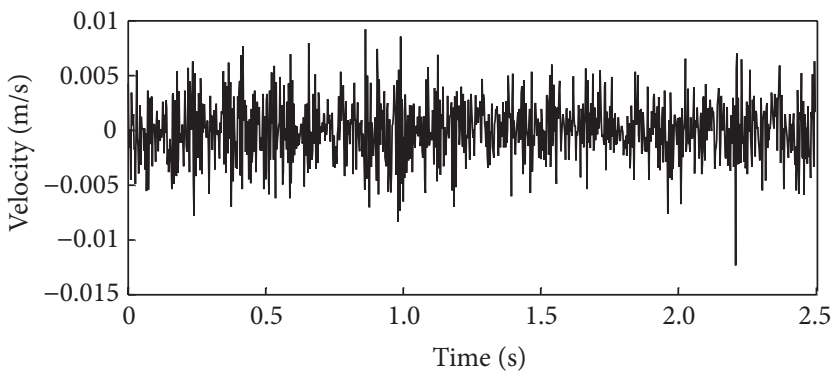

(a) Vibration spectra in time domain

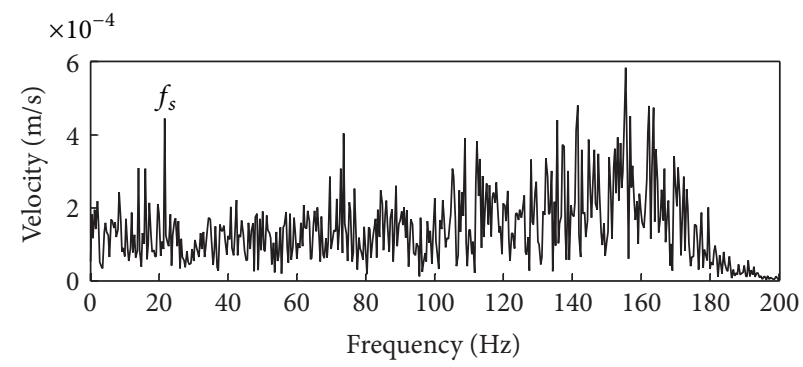

(b) Vibration spectra in frequency domain

FIGURE 5: Vibration responses of healthy (new) test bearing (with dynamic radial load, shaft speed $=1500 \mathrm{rpm}$ ).

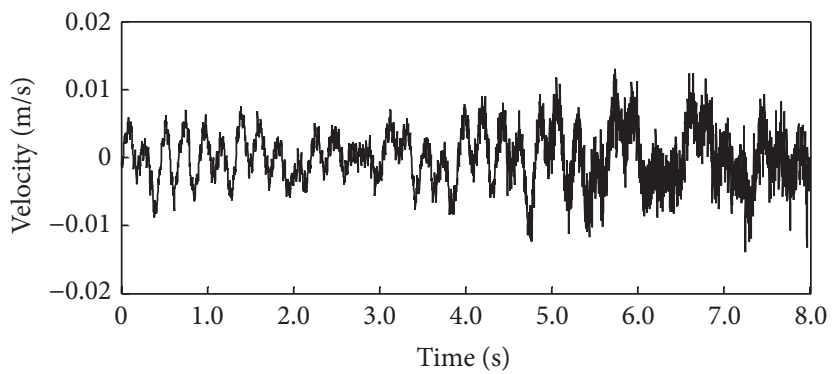

(a) Vibration spectra in time domain

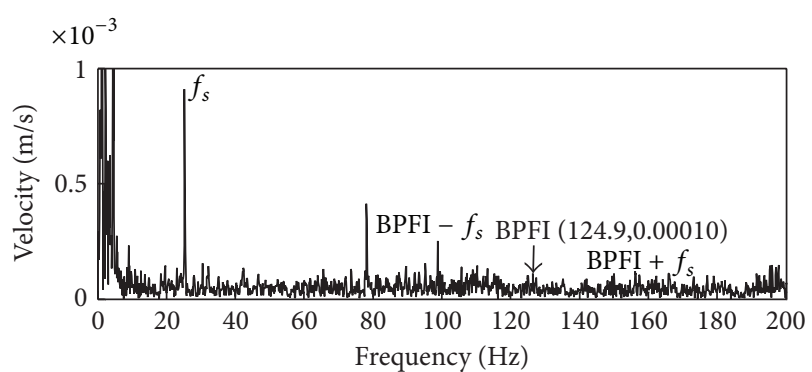

(b) Vibration spectra in frequency domain

FIGURE 6: Vibration response of test bearing having a local circular defect on inner race (with dynamic radial load, shaft speed $=1500 \mathrm{rpm}$, defect diameter $=0.42 \mathrm{~mm}$ ).

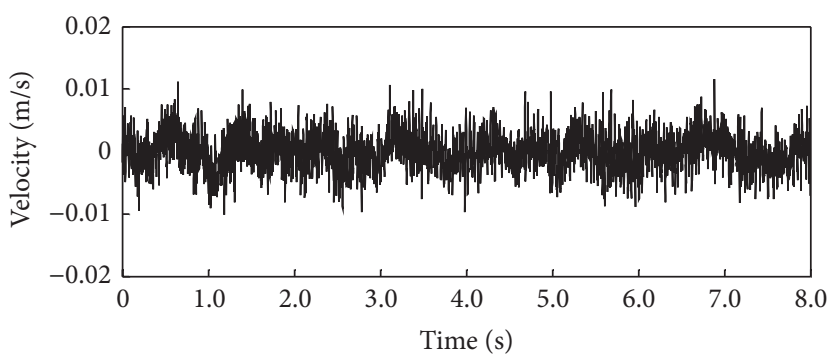

(a) Vibration spectra in time domain

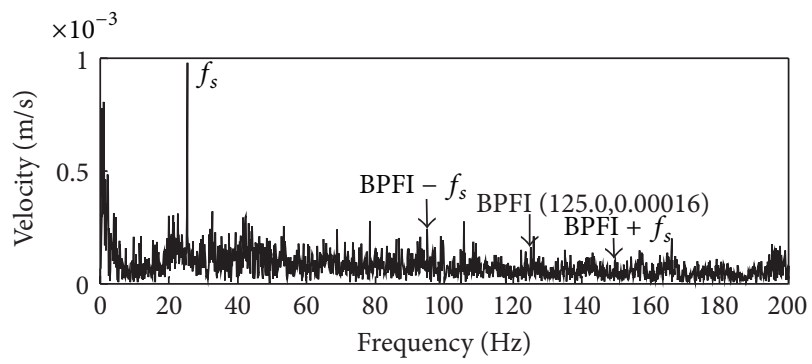

(b) Vibration spectra in frequency domain

FIGURE 7: Vibration response of test bearing having a local circular defect on inner race (with dynamic radial load, shaft speed $=1500 \mathrm{rpm}$, and defect diameter $=0.50 \mathrm{~mm}$ ). 


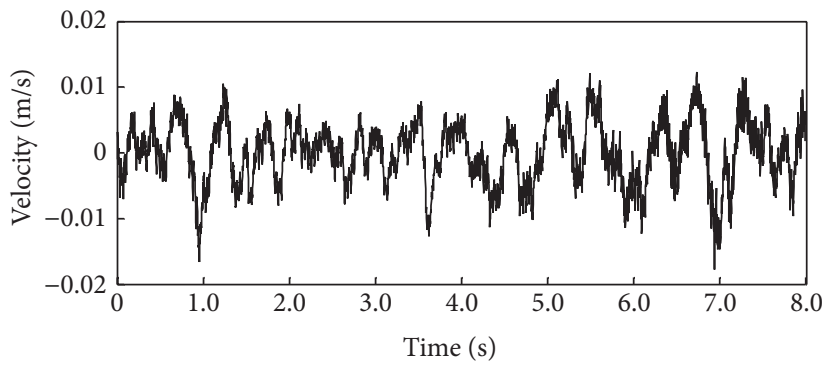

(a) Vibration spectra in time domain

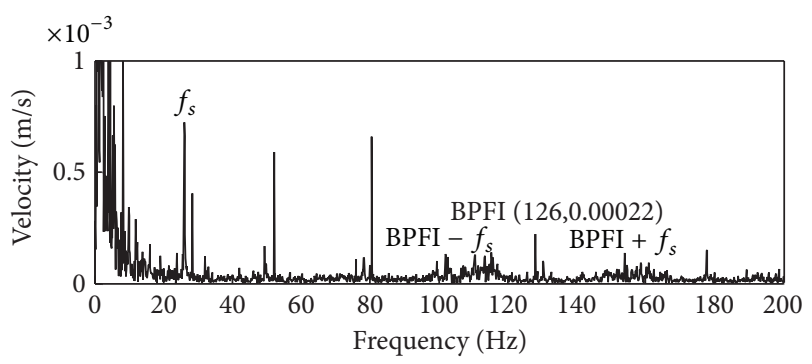

(b) Vibration spectra in frequency domain

FIGURE 8: Vibration response of test bearing having a local circular defect on inner race (with dynamic radial load, shaft speed $=1500 \mathrm{rpm}$, and defect diameter $=0.96 \mathrm{~mm}$ ).

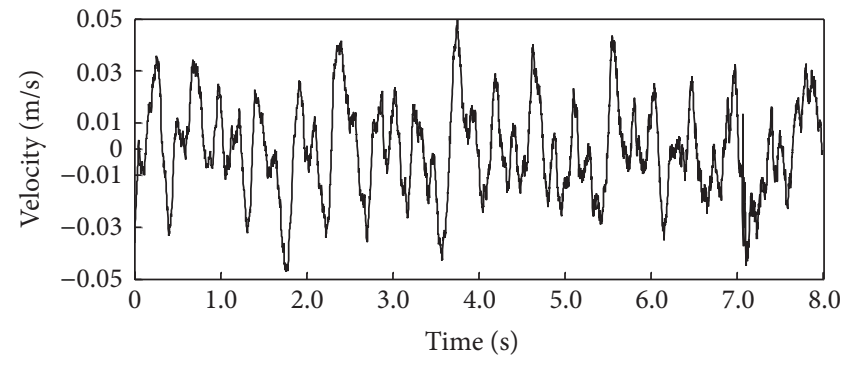

(a) Vibration spectra in time domain

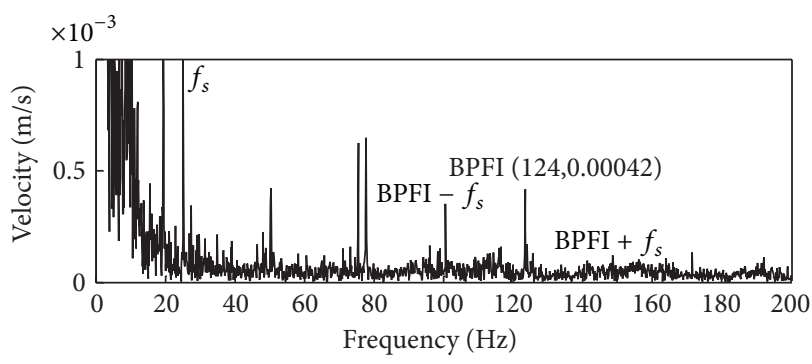

(b) Vibration spectra in frequency domain

FIGURE 9: Vibration response of test bearing having a local circular defect on inner race (with dynamic radial load, shaft speed $=1500 \mathrm{rpm}$, and defect diameter $=1.48 \mathrm{~mm}$ ).

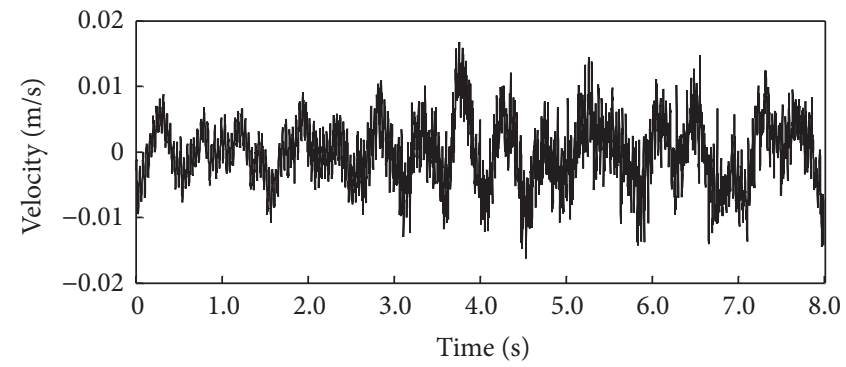

(a) Vibration spectra in time domain

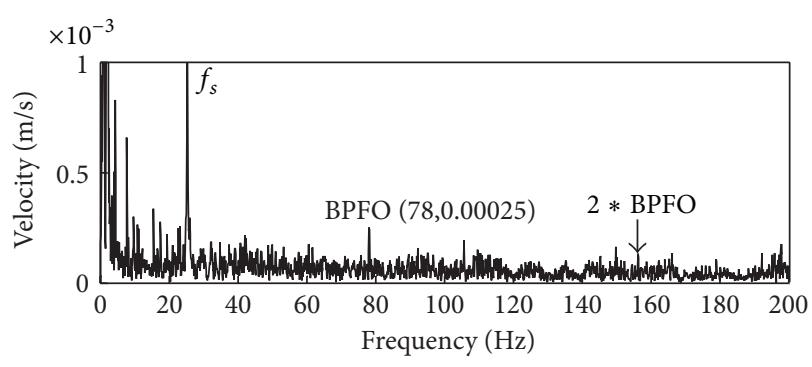

(b) Vibration spectra in frequency domain

FIGURE 10: Vibration response of test bearing having a local circular defect on outer race (with dynamic radial load, shaft speed $=1500 \mathrm{rpm}$, and defect diameter $=0.42 \mathrm{~mm}$ ).

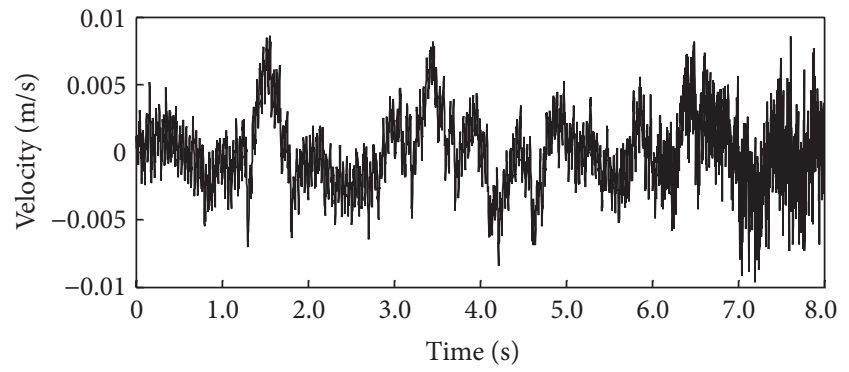

(a) Vibration spectra in time domain

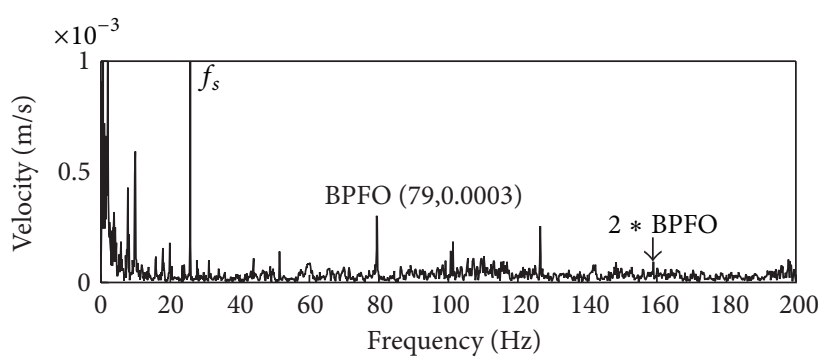

(b) Vibration spectra in frequency domain

FIGURE 11: Vibration response of test bearing having a local circular defect on outer race (with dynamic radial load, shaft speed $=1500 \mathrm{rpm}$, and defect diameter $=0.50 \mathrm{~mm}$ ). 


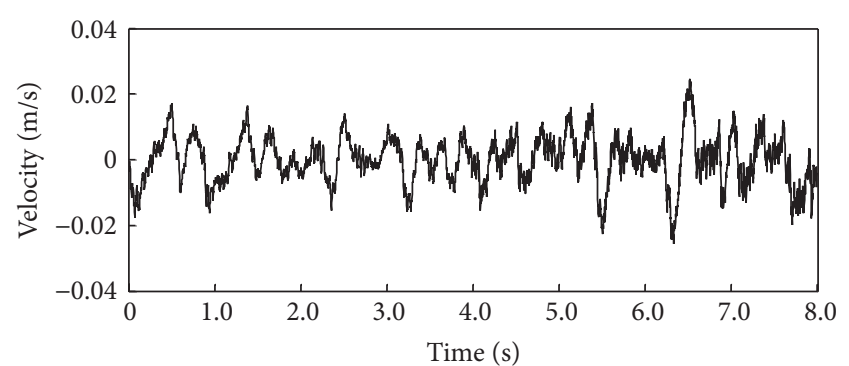

(a) Vibration spectra in time domain

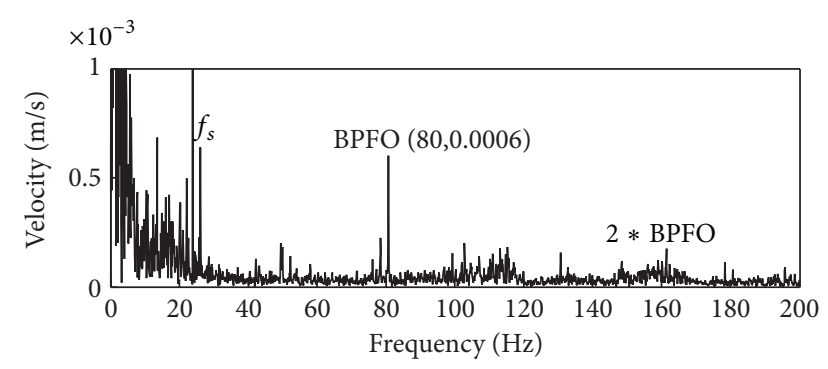

(b) Vibration spectra in frequency domain

FIGURE 12: Vibration response of test bearing having a local circular defect on outer race (with dynamic radial load, shaft speed = $1500 \mathrm{rpm}$, and defect diameter $=0.96 \mathrm{~mm}$ ).

some signal processing techniques like adaptive filtering, envelope analysis, mathematical morphology, and so forth can be implemented $[18,19]$. In another experiment, the defect size has been enhanced to $0.50 \mathrm{~mm}$ and the vibration responses in frequency domain have been captured and presented in Figure 7(b). In this figure, the vibration amplitude at BPFI is enhanced to $0.16 \mathrm{~mm} / \mathrm{s}$. Even this value of the vibration amplitude is getting buried in the vibrations generated due to the dynamic radial load. In additional sets of the experiments carried out for the circular defect diameters of $0.96 \mathrm{~mm}$ and $1.48 \mathrm{~mm}$, the vibrations amplitudes at BPFI have reached $0.22 \mathrm{~mm} / \mathrm{s}$ and $0.42 \mathrm{~mm} / \mathrm{s}$, respectively. These values of vibration amplitudes can be noticed with their side bands in Figures $8(\mathrm{~b})$ and 9(b). The overall vibration levels have also enhanced with increase in the defect size, which can be seen even in the time domain results provided in Figures $8(a)$ and $9(a)$. It is worth mentioning here that the minor variation in BPFI $(123-126 \mathrm{~Hz})$ is due to the difficulty in precisely controlling a constant shaft rotational speed (1500 rpm) during the experiments.

3.2. Bearing with Outer Race Defect. Normally the defects on stationary outer races of rolling bearings happen in the loaded zone due to the occurrence of high repeated stresses. Therefore, the test bearings having defects on outer races were mounted in the housing in such a way that the location of the circular defect must fall in the loaded zone. The vibration spectra of the test bearings having different circular defect diameters $0.42,0.50,0.96$, and $1.48 \mathrm{~mm}$ on their outer races have been presented in Figures 10-13. Series "a" and "b" of these figures illustrate vibration spectra in time domain and frequency domain, respectively. For shaft rotational speed of

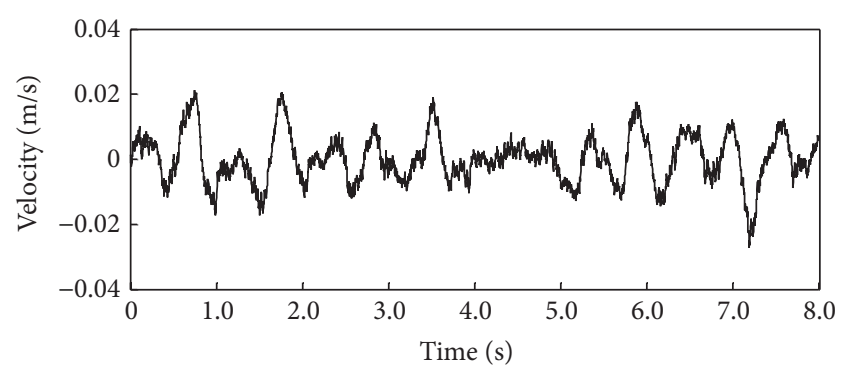

(a) Vibration spectra in time domain

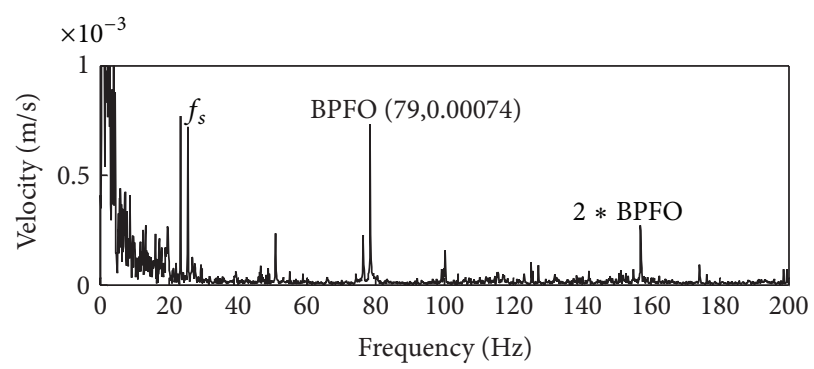

(b) Vibration spectra in frequency domain

FIGURE 13: Vibration response of test bearing having a local circular defect on outer race (with dynamic radial load, shaft speed $=$ $1500 \mathrm{rpm}$, and defect diameter $=1.48 \mathrm{~mm}$ ).

$1500 \mathrm{rpm}$, the ball pass frequency of outer race (BPFO) is calculated as $77 \mathrm{~Hz}$ using the relation $\mathrm{BPFO}=\left(N_{b} / 2\right) \times\left(N_{s} / 60\right) \times$ $(1-d / D)$. With the dynamic radial loading, the vibration response of test bearing having defect diameter of $0.42 \mathrm{~mm}$ is presented in Figure 10. In Figure 10(b), the peaks at shaft rotation frequency $\left(f_{s}\right), \mathrm{BPFO}$, and its second harmonics can be observed. The vibration amplitude at BPFO is $0.25 \mathrm{~mm} / \mathrm{s}$. However, with increase in defect diameters $(0.50,0.96$, and $1.48 \mathrm{~mm}$ ), the corresponding amplitudes of vibrations at the BPFO increase to $0.30,0.60$, and $0.74 \mathrm{~mm} / \mathrm{s}$, respectively. These vibration amplitudes can be seen in Figures 11(b), 12(b), and $13(\mathrm{~b})$. The second harmonics of BPFO are also visible in Figures 12(b) and 13(b) with increase in the defect size; however, this type of visibility could not be noticed in the cases of inner race defects.

\section{Conclusions}

Experimental vibration studies with locally defective deep groove ball bearings have been carried out and reported in this paper by applying dynamic radial loading on the test bearings. Four different circular sizes of defects on either race of bearings have been considered in the investigations for bringing out the broader generality in the observations. Based on the studies reported herein, the following conclusions have been drawn:

(i) with healthy bearing under no load conditions, the vibration peaks at shaft rotational frequency with their harmonics are observed;

(ii) with dynamic radial loading of varying frequency applied on the healthy test bearings, the amplitude of 
vibrations at the shaft rotation frequency gets buried under other types of vibrations;

(iii) overall vibration increases in presence of local defects in comparison to healthy test bearing under dynamic radial loading;

(iv) with increase in the circular defect size, the vibration peaks at BPFI and BPFO are getting visible. This visibility is better with local defects on outer race in comparison to inner race defects.

\section{Conflict of Interests}

The authors declare that there is no conflict of interests regarding the publication of this paper.

\section{References}

[1] L. D. Meyer, F. F. Ahlgren, and B. Weichbrodt, "An analytic model for ball bearing vibrations to predict vibration response to distributed defects," Journal of Mechanical Design, vol. 102, no. 2, pp. 205-210, 1980.

[2] N. Tandon and A. Choudhury, "Theoretical model to predict the vibration response of rolling bearings in a rotor bearing system to distributed defects under radial load," Journal of Tribology, vol. 122, no. 3, pp. 609-615, 2000.

[3] A. Choudhury and N. Tandon, "Vibration response of rolling element bearings in a rotor bearing system due to a local defect under radial load," Journal of Tribology, vol. 128, no. 2, pp. 252261, 2006.

[4] R. Savalia, M. K. Ghosh, and R. K. Pandey, "Vibration analysis of lubricated angular contact ball bearings of rigid rotor considering waviness of ball and races," Tribology Online, vol. 3, pp. 322-327, 2008.

[5] C. K. Babu, N. Tandon, and R. K. Pandey, "Vibration modeling of a rigid rotor supported on the lubricated angular contact ball bearings considering six degrees of freedom and waviness on balls and races," Journal of Vibration and Acoustics, vol. 134, no. 1, Article ID 011006, 12 pages, 2012.

[6] P. D. McFadden and J. D. Smith, "Model for the vibration produced by a single point defect in a rolling element bearing," Journal of Sound and Vibration, vol. 96, no. 1, pp. 69-82, 1984.

[7] P. D. McFadden and J. D. Smith, "The vibration produced by multiple point defects in a rolling element bearing," Journal of Sound and Vibration, vol. 98, no. 2, pp. 263-273, 1985.

[8] Y.-T. Su and S.-J. Lin, "On initial fault detection of a tapered roller bearing: frequency domain analysis," Journal of Sound and Vibration, vol. 155, no. 1, pp. 75-84, 1992.

[9] N. Tandon and A. Choudhury, "A review of vibration and acoustic measurement methods for the detection of defects in rolling element bearings," Tribology International, vol. 32, no. 8, pp. 469-480, 1999.

[10] J. Sopanen and A. Mikkola, "Dynamic model of a deep-groove ball bearing including localized and distributed defects-part 1: theory," Journal of Multi-Body Dynamics, vol. 217, no. 3, pp. 201-211, 2003.

[11] J. Sopanen and A. Mikkola, "Dynamic model of a deep-groove ball bearing including localized and distributed defects-part 2: implementation and results," Journal of Multi-Body Dynamics, vol. 217, no. 3, pp. 213-223, 2003.
[12] A. Choudhury and N. Tandon, "Vibration response of rolling element bearings in a rotor bearing system to a local defect under radial load," Journal of Tribology, vol. 128, no. 2, pp. 252261, 2006.

[13] H. Arslan and N. Aktürk, "An investigation of rolling element vibrations caused by local defects," Journal of Tribology, vol. 130, no. 4, Article ID 041101, 12 pages, 2008.

[14] A. Ashtekar, F. Sadeghi, and L.-E. Stacke, "A new approach to modeling surface defects in bearing dynamics simulations," Journal of Tribology, vol. 130, no. 4, Article ID 041103, 8 pages, 2008.

[15] V. N. Patel, N. Tandon, and R. K. Pandey, "Dynamic model for vibration studies of deep groove ball bearings considering single and multiple defects in races," Journal of Tribology, vol. 132, no. 4, Article ID 041101, 10 pages, 2010.

[16] M. S. Patil, J. Mathew, P. K. Rajendrakumar, and S. Desai, "A theoretical model to predict the effect of localized defect on vibrations associated with ball bearing," International Journal of Mechanical Sciences, vol. 52, no. 9, pp. 1193-1201, 2010.

[17] J. Liu, Y. Shao, and T. C. Lim, "Vibration analysis of ball bearings with a localized defect applying piecewise response function," Mechanism and Machine Theory, vol. 56, pp. 156-169, 2012.

[18] V. N. Patel, N. Tandon, and R. K. Pandey, "Improving defect detection of rolling element bearings in the presence of external vibrations using adaptive noise cancellation and multiscale morphology," Journal of Engineering Tribology, vol. 226, no. 2, pp. 150-162, 2012.

[19] V. N. Patel, N. Tandon, and R. K. Pandey, "Defect detection in deep groove ball bearing in presence of external vibration using envelope analysis and Duffing oscillator," Measurement, vol. 45, no. 5, pp. 960-970, 2012.

[20] V. N. Patel, N. Tandon, and R. K. Pandey, "Vibration studies of dynamically loaded deep groove ball bearings in presence of local defects on races," Procedia Engineering, vol. 64, pp. 15821591, 2013. 

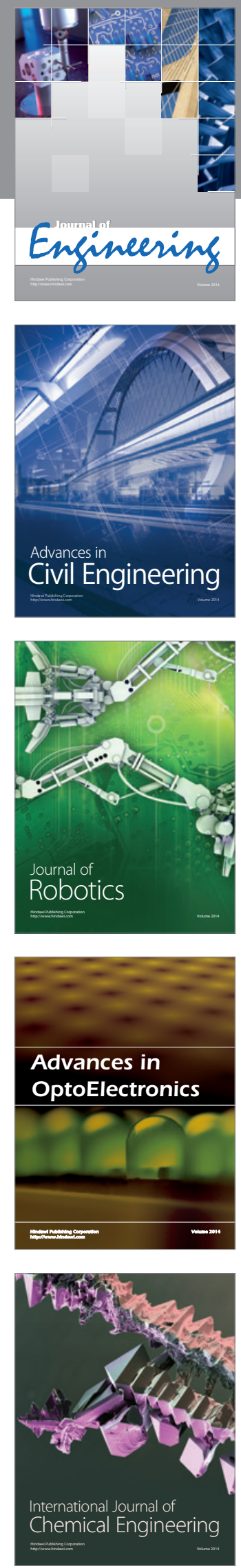

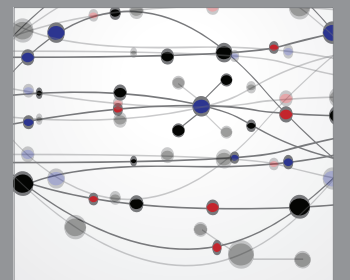

The Scientific World Journal
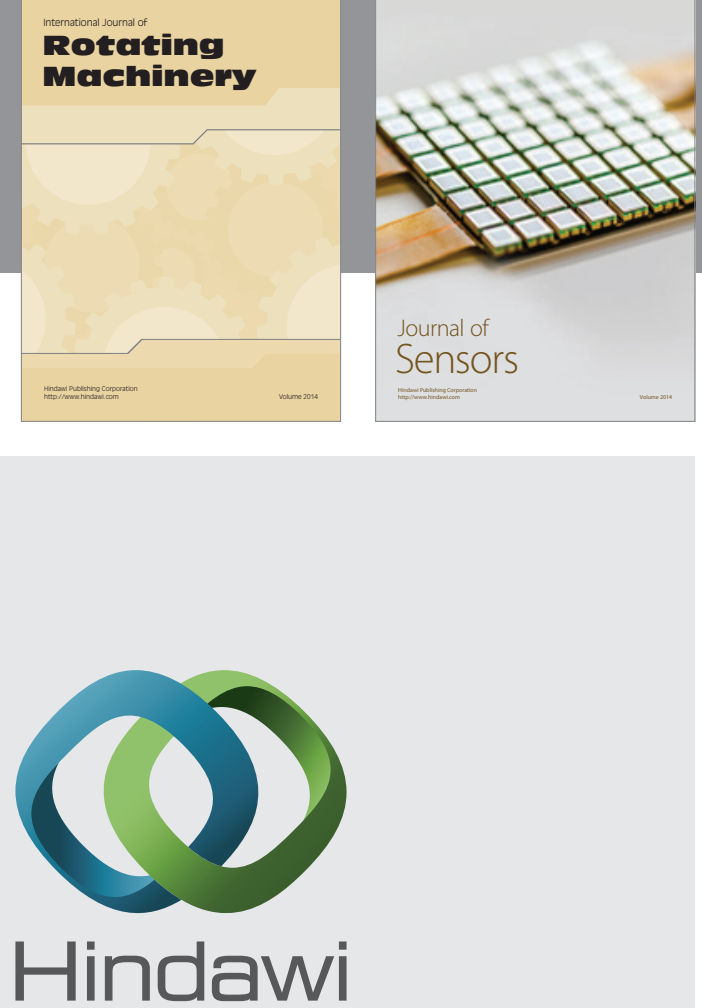

Submit your manuscripts at http://www.hindawi.com
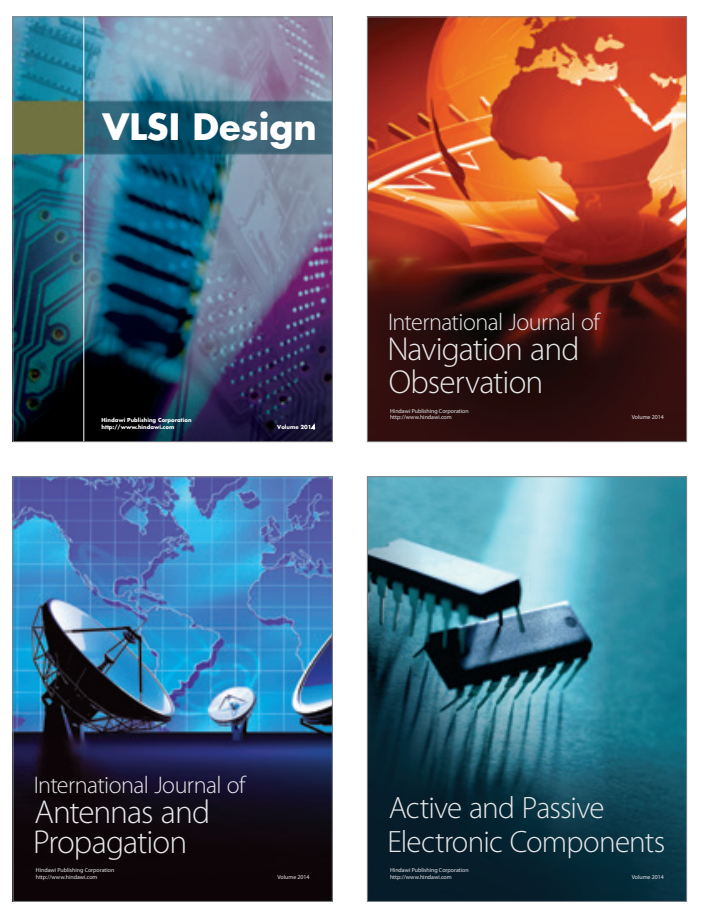
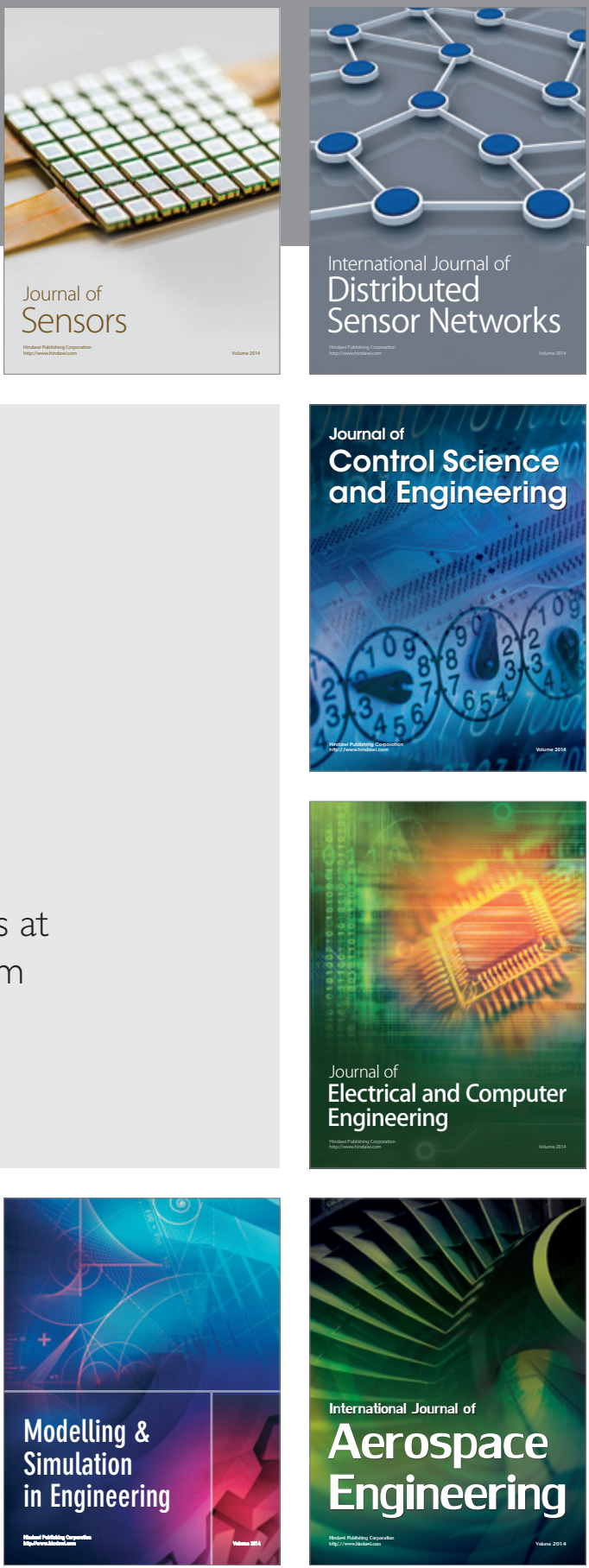

Journal of

Control Science

and Engineering
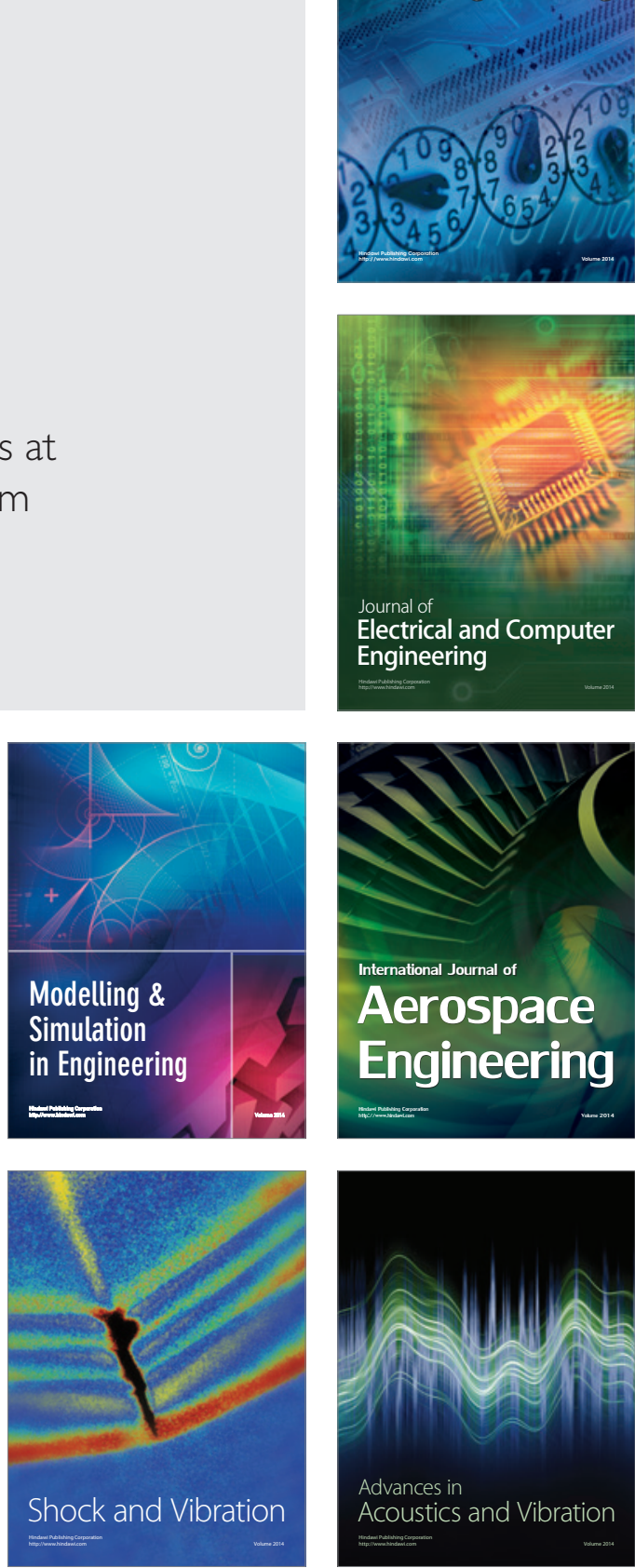